Rev. Bras. Saúde Prod. Anim., Salvador, v.16, n.1, p.73-81 jan./mar., 2015 http://www.rbspa.ufba.br ISSN 15199940

\title{
Níveis de sódio na ração de codornas japonesas em postura
}

\author{
Sodium levels in diet of laying japanese quails
}
LIMA, Heder José D’Avila ${ }^{1 *}$; BARRETO, Sergio Luiz de Toledo ${ }^{2}$; PAULA, Eriane $\mathrm{de}^{2}$; DUTRA, Daniel Rodrigues ${ }^{2}$; COSTA, Sanely Lourenço da ${ }^{3}$; ABJAUDE, Walason da Silva ${ }^{4}$

\author{
${ }^{1}$ Universidade Federal de Mato Grosso, Faculdade de Agronomia, Medicina Veterinária e Zootecnia, \\ Departamento de Zootecnia e Extensão Rural, Cuiabá, Mato Grosso, Brasil \\ ${ }^{2}$ Universidade Federal de Viçosa, Departamento de Zootecnia, Viçosa, Minas Gerais, Brasil \\ ${ }^{3}$ Universidade Federal de Viçosa, Departamento de Medicina Veterinária, Viçosa, Minas Gerais, Brasil \\ ${ }^{4}$ Universidade de São Paulo, Instituto de Ciências Biomédicas, São Paulo, Brasil \\ *Endereço para correspondência: hederdavila@yahoo.com.br
}

\section{RESUMO}

O experimento foi realizado para estimar a exigência nutricional de sódio $(\mathrm{Na})$ para codornas japonesas em postura. Foram utilizadas 245 codornas japonesas, com 187 dias de idade, peso de $189,4 \pm 6,1 \mathrm{~g}$ e taxa de produção de ovos de $91,05 \pm 5,5 \%$. As aves foram distribuídas em delineamento experimental inteiramente casualizado, constituído por cinco rações e sete repetições. Foram formuladas cinco rações experimentais à base de milho e farelo de soja, com cinco níveis de $\mathrm{Na}(0,10 ; 0,15 ; 0,20 ; 0,25$ e $0,30 \%)$. Foram analisados: consumo de ração, produção de ovos por ave ao dia, por ave alojada, de ovos comercializáveis, de ovos viáveis por ave ao dia, peso do ovo, massa de ovos, conversão alimentar por massa de ovos e por dúzia de ovos, componentes dos ovos (gema (g e \%), albúmen (g e \%) e casca (g e \%), variação de peso corporal, viabilidade das aves e gravidade específica. Não foi verificado efeito $(\mathrm{P}>0,05)$ para nenhum dos parâmetros estudados. Sintomas de deficiência de sódio como inapetência, redução da taxa de crescimento, produção e apetite depravado não foram observados, demonstrando que o menor nível de sódio utilizado, $0,10 \%$, não foi prejudicial às aves. A suplementação de $0,10 \%$ de sódio na ração, correspondente ao consumo diário de 26,1 mg de $\mathrm{Na}$ por ave foi suficiente para proporcionar satisfatório desempenho produtivo e qualidade dos ovos de codornas japonesas.

Palavras-chave: Coturnix coturnix japonica, produção de ovos, sal comum

\section{SUMMARY}

The experiment was conducted to estimate the nutritional requirement of sodium $(\mathrm{Na})$ for laying Japanese quails. Were used 245 Japanese quails, with 187 days old, weight of $189.4 \pm 6.1$ $\mathrm{g}$ and egg production rate of $91.05 \pm 5.5 \%$. Birds were distributed in a completely randomized design, consisting of five diets and seven replicates. Five experimental diets were formulated based on corn and soybean meal, with five levels of $\mathrm{Na}(0.10,0.15,0.20,0.25$ and $0.30 \%$ ). Were examined: feed intake, egg production per bird day, egg production per hen housed, commercial eggs, viable eggs per bird day, egg weight, egg mass, feed conversion by egg mass and per dozen eggs, components eggs (yolk, albumen and shell), body weight variation, viability of birds and specific gravity. There were no differences $(\mathrm{P}>0.05)$ for all parameters studied. Symptoms of deficiency as inappetence, reduction in the growth rate and depraved appetite were not observed in this study, demonstrating that the lower level of $\mathrm{Na}$ used, $0.10 \%$, was not adverse to birds. Supplementation of $0.10 \% \mathrm{Na}$ in diet of the birds, corresponding to a daily intake of 26.1 mg / bird was enough to provide good performance and egg quality of Japanese quails.

Keywords: Coturnix coturnix japonica, egg production, salt 
Rev. Bras. Saúde Prod. Anim., Salvador, v.16, n.1, p.73-81 jan./mar., 2015 http://www.rbspa.ufba.br ISSN 15199940

\section{INTRODUÇÃO}

A coturnicultura, termo designado para a criação de codornas, destaca-se como atividade de relevância na avicultura brasileira. As codornas japonesas são aves de produtividade elevada, apresentando peculiaridades em sua alimentação.

A nutrição de codornas tem sido pesquisada visando constantes melhorias nos índices produtivos e, em virtude do progresso genético aplicado a esta espécie, é necessário estabelecer e atualizar constantemente os níveis nutricionais das dietas (BARRETO et al., 2007).

Durante a fase de produção, uma dieta adequada deve atender a mantença, a postura, a massa de ovos, a qualidade do albúmem e da gema e resultar na produção de ovos com boa pigmentação e resistência da casca (ITO et al., 2009). O sódio $(\mathrm{Na})$ é um mineral de extrema importância para a manutenção normal da homeostase celular, além de participar dos processos de absorção e transporte ativo de aminoácidos e glicose. Apesar de sua importância na alimentação das aves, as exigências desse mineral têm sido pouco estudadas, talvez pelo fácil atendimento das necessidades com sal comum ou pelo custo reduzido dessa matéria-prima (COSTA et al., 2008).

Por não haver amplos estudos com exigência de sódio para codornas, rações podem ser formuladas com níveis superestimados, através da inclusão de 0,25 a $0,30 \%$ de sal comum (MURAKAMI et al., 2006). Além de problemas nutricionais, o excesso de sódio na dieta provoca aumento do consumo de água pelas aves, aumentando por sua vez a umidade das excretas, o que pode causar problemas de manejo (COSTA et al., 2008).
Pelo exposto, objetivou-se com a presente pesquisa estimar a exigência nutricional de sódio para codornas japonesas em postura.

\section{MATERIAL E MÉTODOS}

O experimento foi desenvolvido no setor de avicultura do Departamento de Zootecnia do Centro de Ciências Agrárias da Universidade Federal de Viçosa-MG, no período de janeiro a março, com duração de 63 dias. Foram utilizadas 245 codornas da subespécie japonesa, com 187 dias de idade, peso de $189,4 \pm 6,1 \mathrm{~g}$ e taxa de produção de ovos de $91,05 \pm 5,5 \%$.

As aves foram distribuídas em delineamento experimental inteiramente casualizado, constituído por cinco rações e sete repetições, com sete aves por unidade experimental. As codornas foram alojadas em gaiolas (unidade experimental) de arame galvanizado dispostas em escada, com as dimensões de $25 \times 34 \mathrm{~cm}$, fornecendo uma área de $121,4 \mathrm{~cm}^{2} /$ ave.

As gaiolas foram equipadas com comedouros do tipo calha, e bebedouros do tipo nipple com copinho. Como programa de iluminação foi adotado um fotoperíodo natural mais artificial totalizando em 16 horas de luz.

Foram formuladas cinco rações experimentais (Tabela 1), isocalóricas, isoproteicas e isoaminoacídicas, à base de milho e farelo de soja, com cinco níveis de sódio $(0,10 ; 0,15 ; 0,20 ; 0,25$ e $0,30 \%$ ). As exigências nutricionais utilizadas para a formulação das rações das codornas foram baseadas em resultados de experimentos conduzidos no DZO - UFV, conforme Lima et al. (2010). A composição química e os valores nutricionais dos ingredientes utilizados para a formulação das rações foram os descritos por Rostagno et al. 
Rev. Bras. Saúde Prod. Anim., Salvador, v.16, n.1, p.73-81 jan./mar., 2015 http://www.rbspa.ufba.br ISSN 15199940

(2011). O balanço eletrolítico (BE) das rações experimentais foi calculado considerando os valores percentuais dos eletrólitos segundo Mongin (1980).

As gaiolas foram instaladas em galpão, sendo as temperaturas registradas uma vez ao dia (16h00) e a temperatura média e umidade relativa do ar registradas duas vezes ao dia ( $08 \mathrm{~h} 00$ e $16 \mathrm{~h} 00)$. As rações e a água foram fornecidas à vontade, sendo o arraçoamento feito duas vezes ao dia (08h00 e 16h00) durante todo o período experimental.

Tabela 1. Composição percentual e calculada das rações experimentais, na base da matéria natural

\begin{tabular}{|c|c|c|c|c|c|}
\hline \multirow{2}{*}{ Ingredientes (\%) } & \multicolumn{5}{|c|}{ Níveis de Sódio (\%) } \\
\hline & 0,10 & 0,15 & 0,20 & 0,25 & 0,30 \\
\hline Milho moído & 54,27 & 54,27 & 54,27 & 54,27 & 54,27 \\
\hline Farelo de soja $(45,0 \%)$ & 31,89 & 31,89 & 31,89 & 31,89 & 31,89 \\
\hline Óleo de soja & 2,53 & 2,53 & 2,53 & 2,53 & 2,53 \\
\hline Calcário & 7,38 & 7,38 & 7,38 & 7,38 & 7,38 \\
\hline Fosfato bicálcico & 1,05 & 1,05 & 1,05 & 1,05 & 1,05 \\
\hline Mistura mineral $^{1}$ & 0,05 & 0,05 & 0,05 & 0,05 & 0,05 \\
\hline Mistura vitamínica $^{2}$ & 0,10 & 0,10 & 0,10 & 0,10 & 0,10 \\
\hline DL-Metionina $(98,2 \%)$ & 0,33 & 0,33 & 0,33 & 0,33 & 0,33 \\
\hline L-Lisina $\mathrm{HCl}(78,8 \%)$ & 0,20 & 0,20 & 0,20 & 0,20 & 0,20 \\
\hline Antioxidante $^{3}$ & 0,01 & 0,01 & 0,01 & 0,01 & 0,01 \\
\hline Cloreto de colina $(60,0 \%)$ & 0,10 & 0,10 & 0,10 & 0,10 & 0,10 \\
\hline Sal comum & 0,21 & 0,34 & 0,46 & 0,59 & 0,71 \\
\hline Inerte & 1,88 & 1,75 & 1,63 & 1,50 & 1,38 \\
\hline Balanço eletrolítico $(\mathrm{mEq} / \mathrm{kg})$ & 177,7 & 176,9 & 178,9 & 178,1 & 180,1 \\
\hline \multicolumn{6}{|l|}{ Composição Nutricional Calculada } \\
\hline Energia metabolizável (kcal/kg) & 2800 & 2800 & 2800 & 2800 & 2800 \\
\hline Proteína bruta (\%) & 19,30 & 19,30 & 19,30 & 19,30 & 19,30 \\
\hline Lisina digestível (\%) & 1,080 & 1,080 & 1,080 & 1,080 & 1,080 \\
\hline Metionina+Cistina digestível (\%) & 0,864 & 0,864 & 0,864 & 0,864 & 0,864 \\
\hline Triptofano digestível (\%) & 0,226 & 0,226 & 0,226 & 0,226 & 0,226 \\
\hline Treonina digestível (\%) & 0,593 & 0,593 & 0,593 & 0,593 & 0,593 \\
\hline Cálcio (\%) & 3,090 & 3,090 & 3,090 & 3,090 & 3,090 \\
\hline Fósforo disponível (\%) & 0,300 & 0,300 & 0,300 & 0,300 & 0,300 \\
\hline Sódio $(\%)$ & 0,100 & 0,150 & 0,200 & 0,250 & 0,300 \\
\hline Fibra bruta $(\%)$ & 2,660 & 2,660 & 2,660 & 2,660 & 2,660 \\
\hline \multicolumn{6}{|c|}{$\begin{array}{l}{ }^{1} \text { Composição/kg de produto: Manganês: } 160 \mathrm{~g} \text {, Ferro: } 100 \mathrm{~g} \text {, Zinco: } 100 \mathrm{~g} \text {, Cobre: } 20 \mathrm{~g} \text {, Cobalto: } 2 \mathrm{~g} \text {, Iodo } \\
2 \mathrm{~g} \text {, excipiente q.s.p.: } 1000 \mathrm{~g} \text {. } \\
{ }^{2} \text { Composição/kg de produto: Vit. A: } 12.000 .000 \text { U.I., Vit } \mathrm{D}_{3}: 3.600 .000 \text { U.I., Vit. E: } 3.500 \text { U.I., Vit B } \\
2.500 \mathrm{mg} \text {, Vit } \mathrm{B}_{2}: 8.000 \mathrm{mg} \text {, Vit } \mathrm{B}_{6}: 5.000 \mathrm{mg} \text {, Ácido pantotênico: } 12.000 \mathrm{mg} \text {, Biotina: } 200 \mathrm{mg} \text {, Vit. K } \\
3.000 \mathrm{mg} \text {, Ácido fólico: } 1.500 \mathrm{mg} \text {, Ácido nicotínico: } 40.000 \mathrm{mg} \text {, Vit. B }{ }_{12}: 20.000 \mathrm{mg} \text {, Selênio: } 150 \mathrm{mg} \text {, } \\
\text { Veículo q.s.p.: } 1.000 \mathrm{~g} \text {. } \\
{ }^{3} \text { Butil-hidróxi-tolueno. }\end{array}$} \\
\hline
\end{tabular}

Foram avaliados os seguintes parâmetros: consumo de ração (g/ ave / dia), produção de ovos por ave ao dia $(\%)$, produção de ovos por ave alojada (\%), produção de ovos comercializáveis (\%), produção de ovos viáveis por ave ao dia (\%), peso do ovo (g), massa de ovos (g de ovo /ave / dia), conversão alimentar por massa de ovos (kg de ração / kg de ovos), conversão alimentar por dúzia de ovos ( $\mathrm{kg}$ de ração / dz de ovos), componentes dos ovos (gema (g e \%), albúmen (g e \%) e casca (g e \%), variação 
de peso corporal (g), viabilidade das aves $(\%)$ e gravidade específica $\left(\mathrm{g} / \mathrm{cm}^{3}\right)$.

A cada 21 dias foi calculado o consumo de ração, pela diferença entre a quantidade fornecida e as sobras, corrigindo-se eventuais mortalidades nas parcelas. Os ovos foram coletados diariamente pela manhã e a produção média de ovos no período foi obtida computando-se o número de ovos produzidos, incluindo os quebrados, trincados e os anormais, e foi expressa em porcentagem sobre a média de aves do período (ovo / ave / dia) e, sobre a média de aves alojadas no início do experimento (ovo/ave/ alojada). Também foi calculado o número médio de ovos comercializáveis, descontando-se os quebrados, os trincados e os deformados, do total de ovos. Considerando o percentual de ovos comercializáveis ou viáveis foi calculada a produção de ovos viáveis por ave / dia.

Todos os ovos íntegros produzidos durante o $19^{\circ}$; $20^{\circ} ; 21^{\circ}$; $40^{\circ}$; $41^{\circ}$; $42^{\circ}$, $61^{\mathrm{o}} ; 62^{\circ}$ e $63^{\circ}$ dias experimentais, em cada repetição, foram pesados em balança de precisão de $0,001 \mathrm{~g}$ e o peso total obtido foi dividido pelo número de ovos utilizados na pesagem, obtendo-se o peso médio dos ovos.

A massa total de ovos foi obtida multiplicando-se o peso médio dos ovos pelo número total de ovos produzidos no período experimental. Esta massa total foi dividida pelo número total de aves por dia do período, sendo expressa em gramas de ovo por ave por dia ( $g$ ovo/ ave/ dia).

Para avaliação dos componentes dos ovos foram analisados os pesos da gema, do albúmen e da casca em relação ao peso do ovo, durante o $19^{\circ}$; $20^{\circ}$; $21^{\circ}$; $40^{\circ}$; $41^{\circ}$; $42^{\circ}$; $61^{\mathrm{o}} ; 62^{\mathrm{o}}$ e $63^{\mathrm{O}}$ dias experimentais. Para isso, em cada dia, foram utilizados aleatoriamente quatro ovos de cada unidade experimental. Os ovos foram pesados individualmente em balança com precisão de 0,001g. A gema de cada ovo foi pesada e registrada, e a respectiva casca, foi lavada e seca ao ar, para obtenção do peso da casca. $\mathrm{O}$ peso do albúmen foi obtido subtraindo-se, do peso do ovo, o peso da gema e o da casca.

Foram avaliadas as conversões alimentares por dúzia de ovos, expressa pelo consumo total de ração em quilogramas dividido pelas dúzias de ovos produzidos $(\mathrm{kg} / \mathrm{dz})$, e por massa de ovos, que foi obtida pelo consumo de ração em quilogramas dividido pela massa de ovos produzida em quilogramas $(\mathrm{kg} / \mathrm{kg})$.

Todas as aves foram pesadas ao início e ao término do experimento, para determinação da variação de peso corporal. O total de aves mortas foi anotado diariamente e o número acumulado foi subtraído do número total de aves vivas, sendo os valores obtidos, convertidos em percentagem no final do experimento, para determinação da viabilidade das aves.

A gravidade específica foi determinada pelo método de flutuação salina, conforme metodologia descrita por

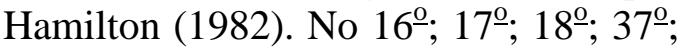

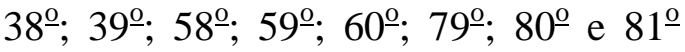
dias dos períodos experimentais, foi avaliada a gravidade específica de todos os ovos íntegros coletados. Os ovos foram imersos em soluções de $\mathrm{NaCl}$ com densidade variando de 1,055 a $1,100 \mathrm{~g} / \mathrm{cm}^{3}$, com intervalos de $0,005 \mathrm{~g} / \mathrm{cm}^{3}$ entre elas. A densidade das soluções foi medida com o auxílio de um densímetro modelo INCOTERM OM - 5565.

As variáveis avaliadas foram submetidas à análise de variância a $5 \%$ de probabilidade utilizando-se o Programa SAEG - Sistema para Análises Estatísticas e Genéticas (UFV, 2007). Posteriormente, os efeitos dos níveis de sódio foram estimados por meio de 
Rev. Bras. Saúde Prod. Anim., Salvador, v.16, n.1, p.73-81 jan./mar., 2015 http://www.rbspa.ufba.br ISSN 15199940

análise das variáveis pelos modelos de regressão linear e quadrática, conforme o melhor ajustamento obtido para cada variável e considerando o comportamento biológico das aves.

\section{RESULTADOS E DISCUSSÃO}

$\mathrm{Na}$ fase adulta, a faixa de conforto térmico ou zona termoneutra das codornas está compreendida entre $18 \mathrm{e}$ $22^{\circ} \mathrm{C}$ e, a umidade relativa do ar, está entre 65 e 70\%, (Oliveira, 2004). As temperaturas máximas e mínimas registradas foram de $30,8 \pm 2,7^{\circ} \mathrm{C}$ e 20,1 $\pm 2,8^{\circ} \mathrm{C}$, a temperatura média do ar foi de $25,6 \pm 3,8^{\circ} \mathrm{C}$ e a umidade relativa do ar foi de $66,3 \pm 13,8 \%$. Dessa forma, conforme os valores registrados para temperatura média do ar e umidade relativa do ar observou-se que durante o experimento, as codornas ficaram submetidas a períodos de estresse por calor. O Balanço eletrolítico de cada ração experimental ficou dentro da faixa recomendada na literatura, não havendo diferenças que pudessem interferir nos níveis de sódio estudados. Balanço eletrolítico de 160 a $190 \mathrm{mEq} / \mathrm{kg}$ tem sido recomendado como ideal para aves de corte (VIEITES et al., 2005).

Não foi verificado efeito $(\mathrm{P}>0,05)$ para nenhum dos parâmetros estudados (Tabela 2). Apesar de em termos absolutos as codornas alimentadas com $0,15 \%$ de $\mathrm{Na}$ apresentarem melhor viabilidade, decorrente da menor mortalidade, observou-se que a maior parte da mortalidade dos outros tratamentos foi decorrente de acidentes em gaiola, o que não é um fator ligado à nutrição e sim ao manejo ou instalação. Conforme Ito et al. (2009), as codornas domésticas ainda conservam muitos caracteres de uma ave selvagem, de modo que o confinamento é suficiente para causar um aumento de mortalidade.

Tabela 2. Desempenho produtivo e qualidade dos ovos de codornas japonesas em função dos níveis de sódio na ração

\begin{tabular}{|c|c|c|c|c|c|c|}
\hline \multirow{2}{*}{ Item } & \multicolumn{5}{|c|}{ Níveis de Sódio (\%) } & \multirow{2}{*}{$\begin{array}{l}\mathrm{CV} \\
(\%)\end{array}$} \\
\hline & 0,10 & 0,15 & 0,20 & 0,25 & 0,30 & \\
\hline Consumo de ração $^{\text {ns }}$ (g/ave/dia) & 26,1 & 26,2 & 25,9 & 26,0 & 25,7 & 3,5 \\
\hline Produção de ovos por ave por dia ${ }^{\text {ns }}(\%)$ & 88,9 & 90,0 & 87,7 & 85,9 & 87,7 & 8,1 \\
\hline Produção de ovos por ave alojada $^{\text {ns }}(\%)$ & 83,7 & 88,2 & 83,9 & 83,2 & 84,3 & 11,0 \\
\hline Ovos comercializáveis ${ }^{\mathrm{ns}}(\%)$ & 98,0 & 98,8 & 97,9 & 97,8 & 98,1 & 1,4 \\
\hline Produção de ovos viáveis por ave/dia ${ }^{\mathrm{ns}}(\%)$ & 87,2 & 88,9 & 85,8 & 84,1 & 86,0 & 8,5 \\
\hline Peso dos ovos ${ }^{\mathrm{ns}}(\mathrm{g})$ & 11,6 & 11,8 & 11,7 & 11,7 & 11,6 & 2,7 \\
\hline Massa de $\operatorname{ovos}^{\mathrm{ns}}$ (g/ave/dia) & 10,3 & 10,6 & 10,3 & 10,0 & 10,2 & 8,8 \\
\hline Conversão alimentar por massa de ovos ${ }^{\mathrm{ns}}(\mathrm{kg} / \mathrm{kg})$ & 2,5 & 2,4 & 2,5 & 2,6 & 2,5 & 7,5 \\
\hline Conversão alimentar por dúzia de ovos ${ }^{\mathrm{ns}}(\mathrm{kg} / \mathrm{dz})$ & 0,35 & 0,35 & 0,35 & 0,36 & 0,35 & 7,1 \\
\hline Gravidade específica $^{\mathrm{ns}}\left(\mathrm{g} / \mathrm{cm}^{3}\right)$ & 1,072 & 1,073 & 1,072 & 1,073 & 1,073 & 0,1 \\
\hline Peso de gema ${ }^{\text {ns }}(\mathrm{g})$ & 3,4 & 3,5 & 3,4 & 3,4 & 3,4 & 2,8 \\
\hline Peso de albúmen ${ }^{\mathrm{ns}}(\mathrm{g})$ & 7,3 & 7,5 & 7,4 & 7,3 & 7,4 & 3,7 \\
\hline Peso de casca ${ }^{\mathrm{ns}}(\mathrm{g})$ & 0,94 & 0,95 & 0,93 & 0,95 & 0,94 & 3,9 \\
\hline Porcentagem de gema $^{\text {ns }}(\%)$ & 29,7 & 29,2 & 29,1 & 29,4 & 29,4 & 2,6 \\
\hline 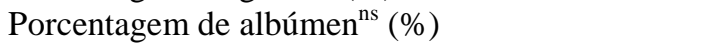 & 62,2 & 62,8 & 63,0 & 62,4 & 62,5 & 1,4 \\
\hline Porcentagem de casca $^{\mathrm{ns}}(\%)$ & 8,0 & 7,9 & 7,8 & 8,1 & 7,9 & 2,7 \\
\hline Viabilidade das aves $^{\text {ns }}(\%)$ & 87,7 & 97,9 & 89,7 & 93,8 & 87,7 & 13,2 \\
\hline Variação de peso corporal ${ }^{1}(\mathrm{~g})$ & 6,3 & $-0,3$ & 0,2 & 1,5 & 2,3 & - \\
\hline
\end{tabular}

${ }^{\mathrm{ns}}$ Efeito não significativo $(\mathrm{P}>0,05)$.

${ }^{1}$ Foi feita análise descritiva desse parâmetro, pois os dados não seguiram distribuição normal. 
Considerando ainda os resultados em valores absolutos, o nível de $0,15 \%$ de sódio proporcionou melhora de 2,02\% na conversão alimentar por massa de ovos e 1,91\% na produção de ovos viáveis por ave / dia em relação a $0,10 \%$ de sódio. Contudo, de maneira geral, principalmente em relação aos parâmetros de qualidade dos ovos, nem mesmo em termos absolutos foi observada variação considerável.

Em se tratando de variação de peso corporal, as codornas alimentadas com o nível de $0,15 \%$ de sódio foram as únicas que tiveram perda de peso, contudo esta variação foi pequena.

Sintomas de deficiência de sódio citados por Bertechini (2006) como inapetência, redução da taxa de crescimento e apetite depravado não foram observados nesta pesquisa. Esta constatação pode ser observada pelos valores de consumo de ração e variação de peso corporal, demonstrando que o menor nível de Na utilizado, $0,10 \%$, não foi prejudicial às aves. Considerando que o sódio esta relacionado à alimentação, Lima et al. (2011) verificaram menor consumo de ração em codornas que passaram pela muda forçada através da restrição dietética de sódio, à $0,017 \%$ da ração. Fisiologicamente o organismo das aves consegue regular o conteúdo de sódio orgânico por meio da absorção e excreção.

Os resultados do presente estudo estão de acordo com os encontrados por Figueiredo et al. (2004), que não observaram diferenças no consumo de ração entre os níveis $(0,11 ; 0,14 ; 0,17$; 0,20 e $0,23 \%$ ) de sódio estudados. Da mesma forma, Murakami et al. (2006), utilizando dietas com níveis de 0,04 a $0,22 \%$ de sódio para codornas japonesas, não observaram diferenças entre o consumo de ração e a produção de ovos obtida com a dieta contendo 0,10 a $0,22 \%$ de sódio.
Trabalhando com exigência de sódio para galinhas poedeiras no final do primeiro ciclo e no segundo ciclo de postura, Ribeiro et al. (2008) não verificaram no final do primeiro ciclo, efeito dos níveis de sódio $(0,08 ; 0,13$; $0,18 ; 0,23 ; 0,28 ; 0,33$ e $0,38 \%)$, sobre o consumo de ração, peso médio dos ovos, conversão alimentar por dúzia de ovos, e gravidade específica. No segundo ciclo os autores não encontraram efeito para gravidade específica e peso médio dos ovos.

Figueiredo et al. (2004) também não observaram diferenças no peso médio dos ovos ao fornecerem dietas suplementadas com sal para codornas japonesas no período de verão. Da mesma forma, Murakami et al. (2006), ao determinarem o melhor nível de sal para codornas japonesas, não observaram diferenças no peso médio dos ovos entre as médias das dietas suplementadas com sal comum (0,10 a $0,22 \%$ de $\mathrm{Na})$.

Outros autores como Barreto et al. (2007) não encontraram diferenças na conversão alimentar por dúzia de ovos entre os níveis 0,$083 ; 0,149 ; 0,215$ e $0,281 \%$ de $\mathrm{Na}$ estudados. Ainda, como no presente trabalho, Murakami et al. (2006) e Barreto et al. (2007) não encontraram diferença para porcentagem de casca.

Pizzolante et al. (2006), verificaram os piores resultados para conversão alimentar por massa de ovos em codornas alimentadas com ração contendo $0,22 \%$ de $\mathrm{Na}$, ao testarem níveis de 0,10 a 0,22\% desse mineral em rações para codornas japonesas em final de produção (54 semanas de idade). Estes autores também não constataram diferenças dos níveis de sódio na dieta sobre peso médio dos ovos, produção de ovos por ave por dia, massa de ovos, consumo de ração e conversão alimentar por dúzia de ovos. Costa et al. (2008), trabalhando com os níveis de 0,$08 ; 0,16 ; 0,24 ; 0,32$ e $0,40 \%$ 
Rev. Bras. Saúde Prod. Anim., Salvador, v.16, n.1, p.73-81 jan./mar., 2015 http://www.rbspa.ufba.br ISSN 15199940

na ração de codornas japonesas em postura, não verificaram efeito no peso médio dos ovos, conversões alimentares por massa de ovos e por dúzia de ovos. Farias et al. (2009) considerando a digestibilidade dos nutrientes e a metabolização da energia, recomendaram que as rações para codornas japonesas na fase de produção sejam formuladas com níveis de sódio entre $0,18 \%$ e $0,24 \%$. Conforme Barreto et al. (2007), a suplementação de $0,281 \%$ de sódio na dieta, correspondente a um consumo diário de $69,1 \mathrm{mg}$ de sódio por ave, melhora o desempenho e a qualidade de ovos de codornas japonesas durante $\mathrm{o}$ pico de produção. No entanto, desempenho satisfatório, calculado com base na produção de ovos por ave ao dia e de ovos comercializáveis, foi obtido com o fornecimento de rações contendo $0,149 \%$ de sódio.

Considerando níveis de sódio, Freitas et al. (2013) verificaram que o aumento desse na ração de codornas de corte de 0,07 para $0,32 \%$ não alterou o $\mathrm{pH}$ e as concentrações de eletrólitos no sangue. Gal-Garber et al. (2003) avaliando o possível aumento da atividade da bomba de sódio e potássio no intestino delgado de aves em função de níveis acentuados de $\mathrm{Na}$, verificaram que existe um limite metabólico de resposta aos níveis desse mineral, não sendo proporcional à sua capacidade absortiva.

Costa et al. (2008) recomendam para codornas japonesas em postura $0,231 \%$ de sódio na ração, correspondente a um consumo diário de 56,6 mg de sódio. Por outro lado, segundo Pizzolante et al. (2006) o nível de 0,10\% de sódio na ração, é suficiente para atender às exigências nutricionais de codornas japonesas em final de produção.

Murakami et al. (2006) trabalhando com níveis de 0,$0 ; 0,15 ; 0,20 ; 0,25 ; 0,30$; 0,$35 ; 0,45 \%$ de sal comum na ração de codornas japonesas em postura verificaram que a inclusão de $0,15 \%$ desse mineral, equivalente ao nível de $0,10 \%$ de sódio do presente estudo, foi suficiente para proporcionar bom desempenho produtivo e qualidade dos ovos.

Pelo exposto, o nível de $0,10 \%$ de sódio na ração foi suficiente para a obtenção de resultados de desempenho e qualidade dos ovos de codornas japonesas similares aos melhores obtivos em outros estudos.

A suplementação de $0,10 \%$ de sódio na ração, correspondente a um consumo diário de 26,1mg de $\mathrm{Na} \mathrm{/} \mathrm{ave} \mathrm{é}$ suficiente para proporcionar satisfatório desempenho produtivo e qualidade dos ovos de codornas japonesas.

\section{REFERÊNCIAS}

BARRETO, S.L.T.; ARAUJO, M.S.; UMIGI, R.T; MOURA, W. C. O.; COSTA, C. H. R.; SOUSA, M. F. Níveis de sódio em dietas para codorna japonesa em pico de postura. Revista Brasileira de Zootecnia, v.36, n.5, p.1559-1565, 2007.

\section{BERTECHINI, A.G. Nutrição de}

Monogástricos. Lavras: Universidade Federal de Lavras, 2006. 301p.

COSTA, F.G.P.; RODRIGUES, V.P.; GOULART, C.C.; NOBRE, I.S.; SILVA, J.H.V. Exigência de sódio para codornas japonesas em postura. In: CONGRESSO BRASILEIRO DE NUTRIÇÃO ANIMAL, 1., 2008, Fortaleza. Anais... Fortaleza, 2008.

FARIAS, N.N.P.; ALVES, M.A.; LIMA, R.C. Efeito dos níveis de sódio sobre a utilização dos nutrientes por codornas japonesas na fase de postura. In: REUNIÃO ANUAL DA SOCIEDADE BRASILEIRA DE 
Rev. Bras. Saúde Prod. Anim., Salvador, v.16, n.1, p.73-81 jan./mar., 2015 http://www.rbspa.ufba.br ISSN 15199940

ZOOTECNIA, 46. 2009, Maringá.

Anais... São Paulo: Sociedade

Brasileira de Zootecnia, 2009.

FIGUEIREDO, G.O.; KATO, R.K.; BERTECHINI, A.G. Níveis de sódio para codornas japonesas (Coturnix coturnix japonica) no verão. In: SIMPÓSIO INTERNACIONAL, 2., CONGRESSO BRASILEIRO DE COTURNICULTURA, 1., 2004, Lavras. Anais... Lavras: Universidade Federal de Lavras, 2004. p.216.

FREITAS, E.R.; FARIAS, N.N.P.; NASCIMENTO, G.A.J.; RODRIGUES, A.M.; QUEIROZ, M.G.R.; RAQUEL, D.L.; LIMA, R.C. Parâmetros sanguíneos e ósseos de codornas de corte alimentadas com diferentes níveis de sódio. Semina: Ciências Agrárias, v.34, n.2, p.845-852, 2013.

GAL-GARBER, O.; MABJEESH, S.J.; SKLAN, D.; UNI, Z. Nutrient transport in the small intestine: $\mathrm{Na}+\mathrm{K}+-$ atpase expression and activity in the small intestine of the chicken as influenced by dietary sodium. Poultry Science, v.82, p.1127-1133, 2003.

HAMILTON, R.M.G. Methods and factors that affect the measurement of egg shell quality. Poultry Science, v.61, p.2022-2039, 1982.

ITO, N.M.K.; MIYAJI, C.I.; MIYAJI, S.O. Redução da Mortalidade na Criação Industrial de Codornas. In: CONGRESSO DE PRODUÇÃO, COMERCIALIZAÇÃO E CONSUMO DE OVOS, 7., 2009, São Pedro. Anais... São Pedro, São Paulo: Associação Paulista de Avicultura, 2009. p.101-109.
LIMA, H.J.D.; BARRETO, S.L.T.; ALBINO, L.F.T.; D.S. MELO;

BALLOD, M.A.; ALMEIDA, R.L. Aproveitamento de nutrientes e de energia da ração de codornas japonesas em postura com o uso de fitase. Revista Brasileira de Zootecnia, v.39, n.7, p.1517-1522, 2010.

LIMA, H.J.D.; BARRETO, S.L.T.; ALMEIDA, R.L. D.S., MELO, COSTA, S.L. Restrição dietética de sódio como método alternativo de muda forçada para codornas japonesas. Enciclopédia Biosfera, v.7, n.13, p.939-948, 2011.

MONGIN, P. Electrolytes in nutrition: a review of basic principles and practical application in poultry and swine. In: IMC NUTRITION CONFERENCE, 3, 1980, Melbourne. Orlando: IMC, 1980. p.1-15.

MURAKAMI, A.E.; SAKAMOTO, M.I.; SOUZA, L.M.G.; FRANCO, J.R.G.; MITUO, M.A.O. Determinação do melhor nível de sal comum para codornas japonesas em postura. Revista Brasileira de Zootecnia, v.35, n.6, p.2333-2337, 2006.

OLIVEIRA, B. L. Importância do manejo na produção de ovos de codornas. In: II SIMPÓSIO INTERNACIONAL DE COTURNICULTURA, 2., 2004. Lavras, Anais... Lavras, M G: Núcleo de Estudos em Ciência e Tecnologia Avícolas, 2004. p.91-96.

PIZZOLANTE, C.C.; SALDANHA, E.S.P.B.; GARCIA, E.A.; DEODATO, A. P.; SOUZA, H. B. A.; SCATOLINI, A. M.; BOIAGO, M. M.; CASTRO, M.; SACCARDO, T.; DIAS, F. E. Níveis de sal comum em rações de codornas japonesas (Coturnix japonica) em final de produção. Ciência Animal Brasileira, v.7, n.2, p.123-130, 2006. 
Rev. Bras. Saúde Prod. Anim., Salvador, v.16, n.1, p.73-81 jan./mar., 2015 http://www.rbspa.ufba.br

RIBEIRO, M.L.C.; SILVA, J.H.V.;

ARAUJO, J.A.; MARTINS, T.D.D.;

COSTA, F.G.P.; GIVISIEZ, P.E.N.

Exigência de sódio para poedeiras no final do primeiro ciclo e durante o segundo ciclo de postura. Revista Brasileira de Zootecnia, v.37, n.7, p.1257-1264, 2008.

ROSTAGNO, H.S; ALBINO, L.F.T;

DONZELE, J.L; GOMES, P.C;

OLIVEIRA, R.F. de; LOPES, D.C;

FERREIRA, A.S; BARRETO, S.L. de

$T$. Tabelas Brasileiras para aves e

suinos: composição de alimentos e exigências nutricionais. 3.ed. Viçosa, MG: Universidade Federal de Viçosa, 2011. 252p.

UNIVERSIDADE FEDERAL DE VIÇOSA - UFV. Sistema de análises estatísticas e genéticas - SAEG.

Versão 9.1. Viçosa, MG, 2007. 59p.

VIEITES, F.M.; MORAES, G.H.K.; ALBINO, L.F.T.; ROSTAGNO, H.S.; ATENCIO, A.; VARGAS JUNIOR, J.G. Balanço eletrolítico e níveis de proteína bruta sobre o desempenho, o rendimento de carcaça e a umidade da cama de frangos de corte de 1 a 42 dias de Idade. Revista Brasileira de Zootecnia, v.34, p.1990-1999, 2005.

Data de recebimento: 28/11/2013

Data de aprovação: 05/02/2015 